DOI 10.37882/2223-2982.2020.08.14

\title{
СОВРЕМЕННЫЕ ТЕНДЕНЦИИ В ОБУЧЕНИИ СТУДЕНТОВ ЯПОНСКОЙ ПИСЬМЕННОЙ РЕЧИ. ИНФОРМАЦИОННО-ТЕХНОЛОГИЧЕСКИЙ ПОДХОД
}

\section{MODERN TENDENCIES IN TEACHING JAPANESE WRITING. INFORMATION-TECHNOLOGY APPROACH}

A. Derkach

Summary: This article is devoted to the problem of information technologies inclusion into the educational process of a modern university which trains specialists with the knowledge of foreign languages. The author, calling the scientific community attention to the global expansion of computer technologies in all spheres of life in Russia, considers that under the influence of digitalization Russian society, in particular, universities communities acquire new social and professionalpersonal subsystems of values which determine students' motivation for the active use of information technologies in studies and in future professional activities.

Moreover, prac tice shows that the introduction of innovations into future Japanese language specialists training is complicated by two main obstacles. The first problem is in the chronic delay of intercultural communication human factor from constantly renewing technical opportunities to increase people's social mobility. Another obstacle is in the contradiction between the students'needs to use digital technologies in their studies and further professional activities and the inertia of tradition-bound educational community.

The ways of overcoming these obstacles, according to the author, is in the detailed development of information technology approach methodology, teaching methods, didactic materials, as well as in the equipment of classrooms with constantly updated computer hardware and gadgets with the elements of artificial intelligence.

Keywords: system of values in information society, computer technologies and artificial intelligence, information-technology approach, academic training of specialists with knowledge of Japanese, competence of intercultural communication in Japanese, methodology and didactic support to information-technology approach implementation.

\author{
Деркач Александр Владимирович \\ К.n.н., дочент, Московский городской педагогический \\ университет \\ derkach.av.28@mail.ru
}

Аннотация: Данная статья посвящена проблеме включения информационных технологий в учебный процесс современного вуза, готовящего специалистов со знанием иностранных языков. Автор, обращая внимание научного сообщества на глобальное распространение компьютерных технологий во всех сферах жизни россиян, утверждает, что под влиянием цифровизации в российском обществе и, в частности, в научно-образовательной среде вузов происходит зарождение новых социальных и профессионально-личностных подсистем ценностей, которые детерминируют мотивацию обучающихся на активное применение НИТ в учебе и будущей профессиональной деятельности.

При этом, как показывает практика, введение инноваций в процесс подготовки будущих специалистов японского языка осложняются двумя основными препятствиями. Первая проблема заключается в хроническом отставании человеческого фактора межкультурного общения от постоянно обновляющихся технических возможностей повышения социальной мобильности людей.

Другое препятствие представляет собой противоречие, сложившееся между потребностью обучающихся использовать в учёбе и дальнейшей профессиональной деятельности цифровые технологии, и инертностью образовательного сообщества, приверженного традиционным методикам обучения.

Пути преодоления этих препятствий, по мнению автора, заключаются в детальной разработке методологии информационно-технологического подхода, обучающих методик, дидактических материалов, а также оснащение учебных аудиторий постоянно обновляющимся парком компьютерной техники и гаджетов с элементами искусственного интеллекта.

Ключевые слова: система ценностей в информационном обществе, компьютерные технологии и искусственный интеллект, информационно-технологический подход, подготовка специалистов со знанием японского языка в вузе, компетенция межкультурного общения на японском языке, методология и дидактическое обеспечение реализации информационно-технологического подхода.
$\mathrm{M}$ етодология развития общей и частных методик подготовки в вузе специалистов со знанием иностранных языков предусматривает постоянное увеличение числа позиций, с которых наиболее полно просматриваются все грани учебного процесса, нацеленного на формирование у обучаемых способности к полноценному межкультурному общению с носителями изучаемого языка [1, с. 5].

Основополагающим здесь, безусловно, являет- ся системный подход, позволяющий, в нашем случае, представить процесс обучения японскому языку как сложную многокомпонентную систему, а также разрабатывать эффективные педагогические модели подготовки специалистов, способных к межкультурному общению. Не менее важен психолого-педагогический подход - раскрывающий сущность психологически ориентированной дидактики и механизмы формирования способностей к межкультурному общению. Рассмотрение положений культурологического и этнопсихологи- 
ческого подходов открывают возможности для обоснования сущности механизмов межкультурной адаптации и преодоления явлений культурного шока и лингвистического барьера. преодоления явлений культурного шока и лингвистического барьера [6, с. 134-174].

Синергетический подход позволяет подробно рассмотреть процесс обучения японскому языку как открытую систему и расширить возможности понимания проблемы через призму определений междисциплинарного характера. Аксиологический подход открывает возможность более подробного исследования механизмов усвоения обучаемыми ценностей другой культуры, а также мотивации будущих специалистов, направленной на их участие в межкультурном общении [2, с.15].

Несомненно, существует гораздо большее количество перспективных положений для исследования процесса подготовки специалистов со знанием иностранных языков в вузе, и чем больше их применяется исследователями, тем полнее становится общая картина учебного процесса. Вместе с тем, более подробно принято рассматривать именно те подходы, которые считаются актуальными на современном этапе развития педагогической мысли.

Следуя этой логике, в настоящее время исследователям, преподавателям и методистам необходимо обратить особое внимание на такой фактор развития всех сфер жизнедеятельности общества, как информационные технологии.

В самом деле, одним из глобальных изменений, происходящих сегодня в российской действительности, является стремительное вхождение России в международное информационное пространство. При этом наше общество становится все более и более информационным, то есть, интенсивно используя цифровые технологии, сопряженные с ГИС Интернет, становится обществом, в котором большинство работающих занято производством, хранением, переработкой и реализацией информации, особенно высшей её формы - знаний [8].

Многие исследователи рассматривают информационное общество, как фазу развития человеческой цивилизации, в которой резко повышается ценность, роль и значение информации и знаний. При этом концепция современного информационного общества представляет его как особой природы надстройку над современным общественным устройством, когда информация, знания и информационные технологии интенсивно проникают и внедряются во все сферы общества [8].

В России в качестве подобных примеров можно при- вести такие события, оптимизировавшие нашу жизнь, как переход всей страны на цифровое телевещание, использование для передвижения людей и машин маршрутизаторов и навигаторов, покупки товаров в интернет-магазинах, приобретение электронных билетов для проезда на транспорте, посещения концертов, театров и спортивных соревнований. Всё большее количество россиян совершает платежи и переводы денег через банкоматы и систему онлайн-банк, записывается на прием к врачам на сайтах поликлиник, пользуется зарплатными карточками, услугами УФМЦ и сайта Госуслуги для оформления личных документов, уплаты налогов, штрафов и многое, многое другое, на что раньше приходилось тратить массу сил, здоровья и личного времени.

Особенно важно отметить и то, что: «... на передовом рубеже этих инновационных трансформаций - наука и образование, которые призваны, с одной стороны, сформировать научный базис для обоснованного целесообразного внедрения нововведений, с другой, обучить инновационной деятельности подрастающее поколение.» [5, с.98].

Таким образом, наше жизненное пространство, в том числе учебная и профессиональная деятельность, все больше наполняются «умными» цифровыми технологиями, несомненно повышающими качество жизни современного человека, и активно формирующими в России прогрессивное, передовое общество. Поэтому сегодня вольно, или невольно к нам приходит понимание того, что оценка деятельности личности в любой социальной сфере, в том числе и сфере иноязычного образования, без анализа ситуации с позиции информационно-технологического подхода может привести к системным ошибкам в определении целей и задач процесса подготовки специалистов, а также к стагнации и кризису его методического обеспечения.

Вместе с тем, в настоящее время мы сталкиваемся с серьезным противоречием, заключающемся в том, что, не смотря на всю свою актуальность для современной теории и методики обучения иностранным языкам, информационно-технологический подход практически мало описан в научной литературе, не велико число методик применения этого подхода в иноязычном образовании, также наблюдается недостаток учебников и учебных пособий, предназначенных для обучения иностранным языкам с использованием потенциала современных информационных технологий.

Более того, сам термин «информационно-технологический подход» требует подробного определения, которое в первом приближении можно вывести путем анализа его компонентов следующим образом.

«Информационный» в данном контексте означает - 
цифровой формат.

«Технологический» - подразумевает достижения НТР в развитии компьютерных технологий т.е., технический компонент инновации, который является основополагающим. При этом очевидно, что в своем сочетании оба термина не просто суммируют передаваемые ими значения «цифровые технологии», а обозначают позицию, с которой ведется мониторинги анализ процесса цифровизации иноязычного образования в России, а также разрабатывается его методическое сопровождение.

Если задуматься о причинах возникновения столь глубокого противоречия, то оно, скорее всего, уходит корнями в консерватизм и инертность большей части человеческого сообщества. Так, например, достижения в области научно-технического прогресса дают возможность современному человеку общаться всё более и более мобильно, т.е. относительно быстро преодолевать пространство и время. Вместе с тем, сегодня всё острее чувствуется диссонанс между темпами развития технического фактора взаимодействия людей: с одной стороны - стремительное развитие средств коммуникации и транспорта (ГИС Интернет, мобильная связь, самолеты, скоростные поезда, системы навигации и т.д.) и, с другой стороны, несовершенство человеческого фактора взаимодействия: отставание в развитии способов и механизмов общения в поликультурном сообществе, недостаток эффективных методик обучения преодолению культурного и языкового барьеров.

Итак, рассматривая процесс развития общества через призму информационно-технологического подхода, мы, прежде всего, видим, что, все происходящие перемены в общественном сознании настолько масштабны и глубоки, что, являются основанием для обновления системы ценностей российского этноса на новом высоко технологичном этапе его развития.

При этом следует уточнить, что ценностями могут быть объекты и явления, их свойства, абстрактные идеи, воплощающие в себе общественные идеалы, и выступающие, благодаря этому как эталон должного [4, с. 244].

Как известно, система ценностей каждого общества включает в себя социальные и личностные ценности.

Социальные ценности - это общепризнанные поведенческие стандарты и законы функционирования общества [5, с.422]. В числе новых социальных ценностей, формируемых информационной средой, сегодня высокая мобильность людей, комфортные условия быта, высокотехнологичное оборудование мест общественного пользования и транспорта (например, наличие Wi-Fi, устройств для зарядки гаджетов, и т.д.), цифровизация производственного процесса и экономия рабочего времени, в том числе за счёт привлечения элементов искусственного интеллекта (переход на четырёхдневную рабочую неделю), увеличение количества свободного времени для активного отдыха и общения с родными и близкими, сбережение природных ресурсов, в первую очередь энергосбережение, и увеличение жизненных ресурсов человека, прежде всего здоровья и продолжительности активной жизни, расширение возможностей для самообучения, творчества и самосовершенствования личности.

При этом с точки зрения мотивации, важным является понятие «ценностная ориентация человека», представляющая собой детерминированные целью устремления, желания и потребности, выступающие для него в качестве важнейших личных ценностей и целей жизнедеятельности [5, с.422].

К новым профессионально-личностным ценностям обучаемых в системе иноязычного образования с позиции информационно-технологического подхода можно добавить: знания, навыки, умения и компетенции в обработке информационных потоков, отборе из них необходимой информации различной культурной кодировки, а также владение информационно-технологическим инструментарием, а именно: новейшими компьютерными программами, приложениями и гаджетами, обеспечивающими мобильность межкультурного общения.

Каждая из приведенных ценностей имеет свои подсистемы. Так компетенция в работе с информационными потоками включает в себя владение навыками компьютерного набора тестов, навыками и умениями подготовки печатного текста к переводу, знаниями и умениями компьютерного редактирования текстов и другие.

Новые ценности и их подсистемы, с каждым днём всё больше становятся нашей реальностью, так как, благодаря революционному прорыву в области развития компьютерных технологий, человек впервые в своей истории создал не просто машину, а интеллектуального помощника, обладающего интерактивностью, а также возможностями для работы с разными по формату информационными материалами, несопоставимыми с человеческим потенциалом по скорости обработки и объемам хранения информации.

Сегодня под воздействием окружающей информационной среды обучаемые самостоятельно осознают, что прежние примитивные электронные «игрушки» ушли в прошлое и на смену им пришли действительно ценные рабочие инструменты, без умелого владения которыми они уже не будут конкурентоспособными на рынке труда. Поэтому студенты сами стараются приобретать передовую технику, программы и приложения, электронные словари и другие необходимые для успешной учебы 
средства.

Кроме того, обучаемые, как правило, сами, по наитию, осваивают новые технологии и способы их применения для повышения уровня своей образовательной мобильности. Например, будущие специалисты со знанием японского языка самостоятельно осваивают раскладку японской клавиатуры, узнают нюансы работы с электронными словарями типа Яркси, осваивают особенности пользования программой Фонетическое руководство и другими приложениями, поддерживающими иероглифическое письмо. Несомненно, подобное стихийное освоение студентами современных достижений информационных технологий малоэффективно. Для этого необходима основательная база дидактических материалов и методического сопровождения в виде продуманных, и научно обоснованных педагогических моделей, и технологий.

Вместе с тем, практика показывает, что не только вышеперечисленные проблемы являются причиной отставания от передовых методик, сегодня ситуацию также осложняют противоречия между технологическими инновациями и традиционными методиками, которые объясняются инертностью всей образовательной системы и консерватизмом значительной части педагогического сообщества.

Таким образом, осознание обучаемыми новых ценностей и их подсистем на уровне потребностей, с одной стороны, запускает механизм реализации достижения детерминированных потребностями целей, а с другой стороны, с приходом новых технологий обостряются противоречия, препятствующие внедрению инноваций в учебный процесс.

Так, например, с развитием компьютерных технологий в письменном формате общения людей произошли существенные, необратимые перемены. Дело в том, что все мы стали гораздо меньше писать тексты от руки, и все больше набираем речевые произведения (CMC coобщения, письма электронной почты, текстов различных приложений) на клавиатурах, подключённых к процессорам, ускоряющим и упрощающим сам процесс письма. Игнорирование данного факта преподавателями и методистами из-за привычки работать по старинке «с мелом и тряпкой» приводит к недооценке того, что уже сегодня даже в бытовых ситуациях умение печатать приобретает большую ценность, чем умение красиво писать от руки. Подобная тенденция отчетливо проявляется и в производственной, и в учебной сферах деятельности будущего специалиста.

Так тексты переводов, которые производит для заказчика переводчик должны быть предоставлены в печатном виде. Кроме того, тексты курсовых и дипломных работ, документов служебной переписки и т.д., также должны быть напечатаны с соблюдением определенных норм. То есть, умение работы с печатным текстом является ценностью профессионально-личностного характера, и студенты также самостоятельно приходят к пониманию того, что текст является ядром процесса коммуникации, и именно по этой причине сегодня актуально, прежде всего осваивать способы работы с текстом с использованием цифровых технологий, а точнее его компьютерного набора, редактирования и подготовки к переводу. Таким образом получается, что обучающиеся на начальном этапе должны сами определять приоритетные задачи для своевременного овладения японской системе письма с помощью НИТ.

Вместе с тем, общеизвестным фактом является положение о том, что японская система смешанного письма КАНДЗИ КАНА МАДЗИРИБУН ЯВЛяется одной из самых сложных в мире и очень трудоёмкой в плане овладениями навыками и умениями письма для иностранцев. Если слоговыми азбуками Хираганой и Катаканой ещё можно овладеть достаточно твёрдо, то иероглифы в силу их большого количества и графической сложности всегда представляют собой трудно преодолимое препятствие для кодирования и декодирования японского текста. В современном японском языке насчитывают около 50000 иероглифов. Из них установленный правительством Японии в 1981 году обязательный иероглифический минимум «тоё-кандзи» - 1945 иероглифов [2, с. 64].

Непривычным является и само расположение японского текста (сверху - вниз, справа - налево). Восприятие таких текстов русским студентам затрудняет и тот факт, что в них, между словами в предложении нет пробелов, нет знаков переноса части слова на другую строку. Для начинающих изучать японский язык предложение выглядит, как сплошная лента, состоящая из самых разнообразных знаков.

Слоговые азбуки хирагана и катакана, хотя и похожи друг на друга по своей структуре, имеют совершенно различное графическое оформление, при этом в современном варианте в каждой из азбук насчитывается по 46 букв.

Все эти многочисленные особенности неимоверно осложняют процесс самостоятельного научения компьютерному набору японских текстов и требуют методической проработки с целью создания методик и дидактических материалов для качественного овладения навыками и умениями письма в цифровом формате.

Кроме того, так как обучение письму и чтению на японском языке во многом осложняется, прежде всего, так называемой проблемой «сопротивления письменных знаков», в соответствующих методиках уже давно 
разработаны тактика и стратегия преодоления этого сопротивления. Однако процесс продолжает оставаться архитрудоемкими. Наиболее продвинутые методики стараются охватить весь потенциал человеческой психики, начиная с мнемотехники и способов задействования ресурсов подсознания, заканчивая технологиями культурологического характера с социолингвистическим или лингвострановедческим уклоном.

Так, например, Федянина В.А., автор работы «Лингвострановедческий компонент по истории и культуре Японии», успешно применяет методику рационального использования потенциала смежных учебных дисциплин для формирования у студентов лингвострановедческой компетенции на занятиях по истории и культуре Японии. При этом методика предусматривает проведение в ходе лекции практического тренинга чтения культурно маркированной лексики с подробным толкованием её этимологии и коннотации [6].

Авторы различных учебных пособий и справочников, как, например, Кузнецова С.М. и Савинская А.В. в своем сборнике иероглифических упражнений, пытаясь довести до совершенства традиционные методики обучения японскому письму, эффективно комбинируют техники сознательного и прямого способов обучения иностранным языкам [3].

При этом ими безусловно учитывалась психологическая особенность, заключающаяся в том, что, как для иностранцев, так и для самих японцев процесс декодирования иероглифов, т.е. распознавания или в конечном счёте чтения всегда был легче, чем процесс кодирования т.е., их воспроизведения репродукции, или написания. В соответствии с этой иерархией сложности и методические усилия преподавателей и усилия обучаемых более концентрируются на овладение умением воспроизводить иероглифический текст и в меньшей степени учиться его распознавать, так как сам факт возможности воспроизвести иероглифа по памяти уже считается почти полной гарантией умения его адекватного восприятия.

Наряду с этим, на протяжении всей истории после того, как иероглифы вошли в систему японского языка и долгое время к ней адаптировались, меняя структуру лексики и даже грамматики, японцы в течение нескольких столетий испытывали большие затруднения в письменной форме коммуникации. Однако после того, как система письма окончательно сложилась многочисленные попытки отказаться от иероглифики (Деятельность Обществ хираганы, катаканы, латиницы) остались безуспешными. Наивно полагать, что они могут быть заменены чем-либо и в наши дни. Иначе японцы, как они говорят, перестанут быть японцами.

Совсем другой подход к решению этой проблемы стал возможен с момента применения к процессу преодоления сопротивления иероглифических текстов возможностей компьютерных технологий. Буквально за последние 20 лет от скептических усмешек мы пришли к полномасштабному применению цифровых технологий в обработке иероглифики и сегодня умные программы не только позволяют нам печатать иероглифы без какихлибо особых трудностей, но и определять их чтения и значения, а при отсутствии информации о предъявляемом иероглифе, вообще просто нарисовать его на экране мышкой или стеком в любой последовательности и компьютер напечатает его, т.е. выполнит самую трудоемкую и рутинную часть работы с иероглифическим текстом.

Таким образом в настоящее время в методике обучении японской системе письма, благодаря компьютерным технологиям, смещаются приоритеты методических усилий с продуктивных на рецептивные.

Всё это означает, что происходит перестановка местами приоритетов письма и чтения, влекущая за собой облегчение работы с японскими текстами и более свободную коммуникацию посредством письма. Кроме того, в условиях постоянного дефицита учебного времени, высвобождаемый когнитивный ресурс может быть использован для обучения говорению, аудированию и чтению.

Итак, сегодня с помощью информационных технологий сбываются мечты многих поколений японцев и иностранцев, изучающих японский язык. Это уже объективная реальность, которую нельзя игнорировать чтобы не стать не конкурентноспособным на рынке образования и труда.

Что же касается умения писать иероглифы от руки, то, наверное, это уже теперь проблемы искусства каллиграфии и стилистики, т.е. реализации эстетической функции японского языка.

Итак, в настоящее время в системе профессионального иноязычного образования, ориентированного на подготовку специалистов японского языка к межкультурному общению, необходимо разрабатывать и включать в учебный процесс методики, формирующие такие профессионально-необходимые знания, умения и навыки письма как печатный набор текстов исходного и переводящего языков, редактирование и подготовка японского и русского текстов к переводу. Подчеркнём, что прийти к этому важному выводу нам помог анализ ситуации с позиции информационно-технологического подхода.

Также необходимо отметить, что в связи с глобальной активизацией процессов цифровизации и видео- 
лизации во всех странах мира, в том числе и в Японии, возникают новые форматы для общения представителей разных культур и это означает, что необходимы разработка и внедрение в учебный процесс новых методик подготовки специалистов, востоковедов, переводчиков, учителей и др. в вузе., в основе которых теория и практика информационных технологий. Их потенциал позволит создать благоприятные условия для успешной социализации личности и появления возможностей для достойной самореализации каждого человека.

\section{ЛИТЕРАТУРА}

1. Гальскова Н.Д., Гез Н.И., Теория обучения иностранным языкам. - М., 2006. - С. 5.

2. Деркач А.В., Формирование компетенции межкультурного общения у будущих специалистов японского языка. Петропавловск-Камчат.: КамГУ им. Витуса Беринга, 2010. - 122 с.

3. Кузнецова С.М., Савинская А.В., Иероглифический минимум к учебнику «テーマ別中級から学ぶ゙ 日本語.»: сборник упражнений / авторы-сост.: С.М. Кузнецова, А.В.- М.: МГПУ, 2017. - 272 с.

4. Словарь / Под. ред. А.В. Петровского // Психологический лексикон. Энциклопедический словарь в шести томах / Ред.-сост. Л.А. Карпенко. Под общ. ред. А.В. Петровского. - М.: ПЕР (Э, 2005. - 251 c.

5. Пидкосистый П.И. Словарь-справочник по педагогике. - М., 2004. - 343с.

6. Тарева Е.Г., Коммуникативный подход: в поисках лингводидактических инноваций. Научно-методический журнал: Педагогическое образование и наука, 2014. № 5, С 98.

7. Федоров В.В. Лингвистические и экстралингвистические параметры англоязычной газетно-журнальной публицистики Восточной Азии: дис. ... д-ра филол. наук / В.В. Федоров. - Нижний Новгород, 2019. - 401 с.

8. Федянина В.А., Лингвострановедческий компонент содержания занятий по истории и культуре Японии. Вестник Московского городского педагогического университета. Серия: Филология. Теория языка. Языковое образование. 2010. № 2 (6). С. 99-104.

9. odiplom.ru lab/informacionnoe-obszestvo.html

(с) Деркач Александр Владимирович (derkach.av.28@mail.ru)

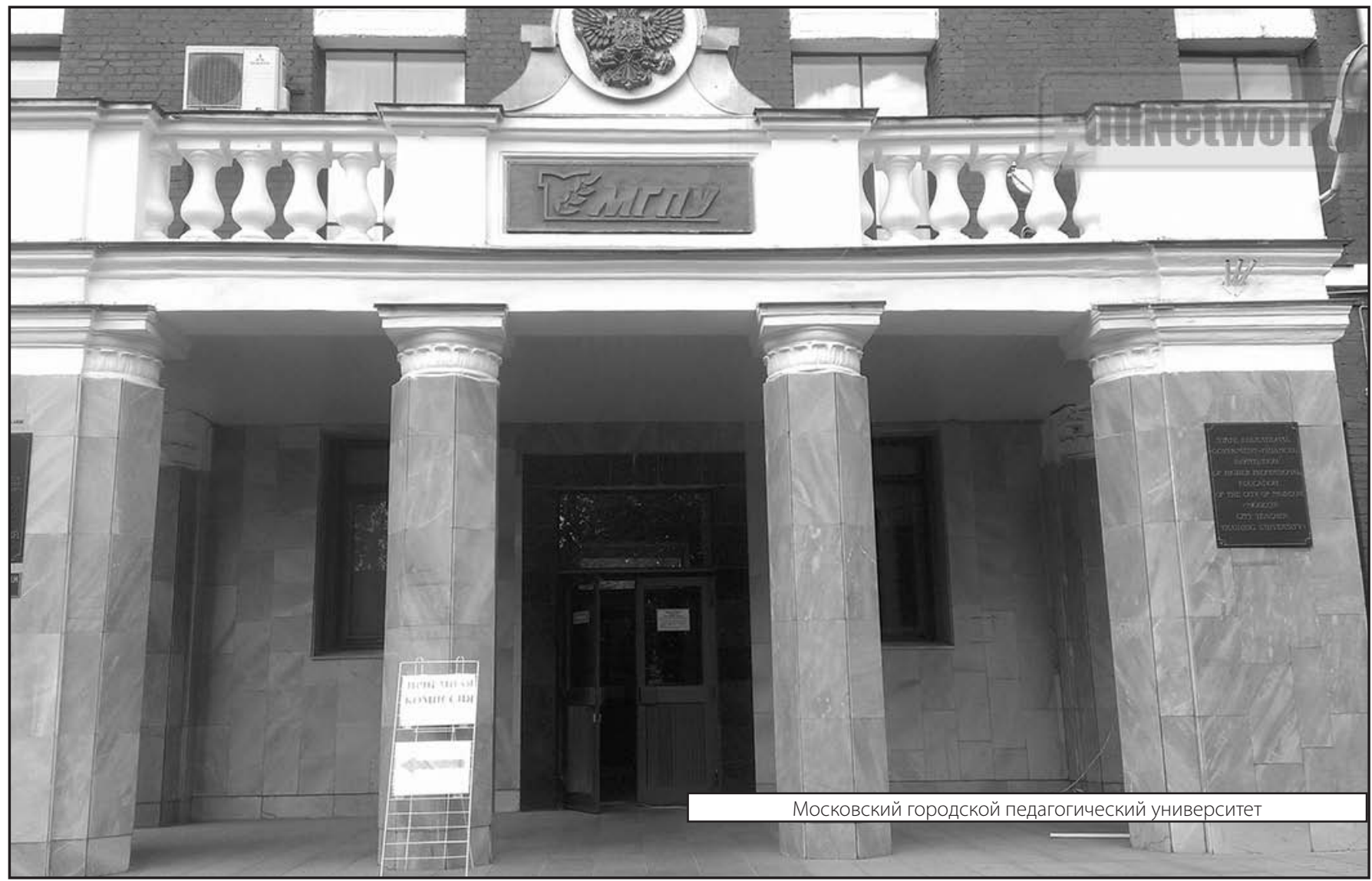

